Beyond risk factors: Towards a more holistic prevention paradigm for children and young people

\author{
Alan France \\ Loughborough University \\ Kate Freiberg \\ Griffith University \\ Ross Homel \\ Griffith University
}

Submitted to the British Journal of Social Work

April 2009

Notes:

1. This is a draft paper submitted for review, and may change in material ways before publication.

2. Authors are listed alphabetically. 


\begin{abstract}
Since the mid 1990s early intervention and prevention has become a central feature of public policy across the western world. This development has had a major impact on re-constructing the prevention paradigm in children and youth services. It has been underpinned by the emergence of the science of risk factor analysis (RFA). Across public policy this paradigm of early intervention and prevention has had mixed success in prevention work but has gained significant political credence and support. While RFA has reshaped prevention approaches it does have methodological, political and practice limitations. This paper argues for a more holistic approach to prevention policy and social work practice, one that recognises risk but does not allow it to dominate. We explore the growing body of evidence for RFA, outlining both its strengths and weaknesses and show how a more holistic approach needs to be adopted, one that recognises the social and cultural context of developmental pathways and the societal access points that fundamentally shape the pathways of children and young people. We draw on the Australian Pathways to Prevention programme to illustrate how social work can and should be developed to create more holistic approaches to prevention.
\end{abstract}




\section{Beyond risk factors: Towards a more holistic prevention paradigm for children and young people}

\section{Introduction:}

Throughout the twentieth century social science has sought to make a contribution to prevention policy by constructing an evidence base that, amongst other applications, highlights the critical stages when intervention in childhood is needed to avoid future social problems. In more recent times social prevention has been shaped by risk factor analysis (RFA) which has had significant political support as a method of identifying and intervening in the lives of those most at risk of becoming future social problems.

This paper starts from a position that RFA is a narrow approach and one that, while generating an expanding evidence base, is unable to provide an effective foundation for tackling future social problems. In the first part of the paper we outline the forces that have put RFA on to the policy map and into social work practice. In this discussion we highlight the growing evidence of its limitations and how it can be used, and is sometimes abused. In the second part of the paper we theorise on the life course and on developmental prevention, outlining the importance of understanding relational developmental systems and especially “mutually influential, individualcontext relations" that are the central tool for exploring the links over the life course between individual psychology and ever-changing social contexts, societal structures, and human culture (Lerner \& Overton, 2008, p. 246). Understanding this is, we argue, critical if prevention policy and practice are to engage effectively with contemporary theory and research and to contribute to sustained, positive change for children and young people, especially those living in socially deprived circumstances. Finally, we 
illustrate how this theorising of developmental systems and the life course can be moved from theory into practice by focusing on the Australian-based Pathways to Prevention programme. In this discussion we show how a programme set in a disadvantaged community that aims at promoting 'pathways to wellbeing' and at opening up “societal access routes” (France \& Homel, 2006) can begin to create the conditions in which individually and socially beneficial changes are easier to achieve in the pathways children and young people take across the life course.

\section{The emergence of a 'new' prevention paradigm}

Over the years social science disciplines involved in the enterprise of prevention have included developmental psychology, life-span sociology, public health, developmental criminology, and life history research (Elder et al., 2004; France and Homel, 2006). Although numerous methodologies are employed in these fields, longitudinal research studies have been particularly important. These have often been conducted within a health science or developmental psychology framework (e.g., the Christchurch Health and Development Study (Fergusson \& Horwood, 2001) and the Australian Temperament Project (Prior et al., 2001). Some of these studies have given rise directly to preventive interventions. For example, on the basis of the findings from the CHDS the Early Start program was developed. (Fergusson et al., 2005). More recently, prevention has been reshaped by the emergence of risk factor analysis (RFA) (France and Utting, 2005). This approach has a long history going back to the work of Cyril Burt in the 1920s, yet it was in the 1990s when it emerged as a major force in prevention research. Again developmental criminology has been a key influence although work by J. David Hawkins and Richard Catalano from the social 
work department at the University of Washington's Social Development Research Group (SDRG) has also had a major influence (Hawkins et al, 2002). The approach of these researchers is more holistic in that it aims to tackle a range of social problems such as substance abuse, school drop out, delinquency, teen pregnancy, and violence as well crime. Risk factors are associated with the probability of a negative outcome. This approach was influenced by developments in public health where unhealthy behaviours such as smoking, fatty diets, and lack of exercise are known to increase the risk of heart disease. Developmental criminologists and others have since used this paradigm to explore the relationship between risk factors and offending. Within this model causal pathways are seen as complex, and prediction at the individual level remains problematic, yet at a group level the evidence seems strong suggesting those children and young people with multiple risk factors are more likely to be offenders in the future (Farrington, 2002).

Much of the work on social prevention has evolved in the US although a number of key research studies have come from the UK (see West and Farrington, 1977) and, as we have noted, from New Zealand (see also Moffitt, 1993). More recently developmental social scientists have helped to create a new discipline of 'prevention science' www.preventionscience.org led by the Society of Prevention Research. This new science aims to bring together a wide range of disciplines to research and understand prevention:

In the UK RFA has had a major impact on social science and preventive practice, an impact that is growing. West and Farrington's longitudinal study of East End boys in the 1950s has provided a wealth of scientific evidence showing the relationship between risk factors and future social problems (Farrington, 2002). Measuring the 
level of risk factors in the UK was also undertaken by the Joseph Rowntree Foundation, drawing attention to, and using the risk factor model for analysis (Beinart et al., 2002). Since its emergence as a feature of social science RFA has grown in stature in terms of recognition. Clinical and developmental psychologists and health scientists, in particular, draw upon RFA to make connections between risk factors and future social problems (for example, poor parenting in the early years and future drug problems or unhealthy life styles) or to define the characteristics of those most troubled ('high or low risk’ adolescents).

\section{Risk factors and the shaping of prevention policy and practice}

Part of the reason for this expansion of RFA is political (France, 2008). As suggested earlier, RFA is not a late modern discovery yet its recent influence on social policy has been enormous. Part of this arises from improved science, but it is also the case that since the 1990s politicians across the globe have been searching for scientific solutions that would help them address a wide range of large-scale social problems. For example, it is no accident that the work of West and Farrington (which has been around since the 1960s) found favour with the UK government in the 1990s.

Politicians and civil servants were seeking an evidence-based approach to reduce high levels of youth crime. RFA and political necessity, it would seem, came together and found common ground.

RFA's acceptance within international political discourses of prevention is partly due to the work undertaken by Hawkins and Catalano in promoting their Communities that Care (CTC) intervention programme (Hawkins et al., 2002). This approach takes RFA as central to understanding how social order in communities is structured. It is 
focused not only on building a strong risk factor evidence base, but also providing community based solutions (interventions) for tackling future social problems. In the US over 600 CTC programmes have been set up in many states. More recently, the programme was adopted by the US government's Center for Substance Abuse $\underline{\text { Prevention (CSAP) }}$ in the office of the United States Government's Substance and Mental Health Services Administration (SAMHSA). It has become mainstreamed in the US as a major intervention programme, and its appeal has also expanded across national boundaries. For example, in the UK, JRF funded the evaluation of three pilot projects (Crow et al., 2004) and the establishment of the CTC organisation in the UK has seen over 50 projects being set up. Similar developments have taken place in the Netherlands (Jonkman et al, 2005) and Canada (http://www.gov.bc.ca/mcf/), where substantial government funding is being devoted to developing risk prevention approaches using the CTC model.

While CTC has expanded its work in the UK, RFA in government prevention policy has also grown. Early Intervention and Prevention has become a key policy area. For example in the 2002 UK Spending Review it was recommended that prevention services become more mainstream so that they could address the recognised risk factors (HM Treasury, 2002). As a result RFA took a central place in the delivery of Children's Services across the UK leading to the creation of strategies that would identify, refer and track those children most 'at risk'. This re-focusing of Children's Services towards social prevention for those 'at risk' was further emphasised in the Every Child Matters legislation (DfES, 2003) and the new Children's Plan (DCSF, 2008) where social prevention becomes a core responsibility of those agencies delivering not only child protection services but all services to children and young 
people. The language and principles of prevention built upon RFA has therefore become a central feature of national policy towards children and young people.

One impact of this, at the level of practice, has been the growth and expansion of risk assessment tools across a wide range of services that work with children and young people (Crisp et al, 2005; Webb, 2006). One major development has been the creation of the Common Assessment Framework (CAF), while this is constructed and framed around need, risk factors are important to the assessment process (Berry, 2007). Similarly, in Youth Justice we see the development of the ASSET assessment process. This is derived from RFA and shaped by the Youth Justice Board's desire to have scientific methods for making assessment of those most 'at risk'. Its central features are to identify the level of risk a young person may have of re-offending or harming others which is then interpreted by drawing on risk analysis evidence (Baker, 2007). Similar trends can be seen in psychiatry where screening programmes and assessment processes are being developed to help identify children with risks of future mental health problems (Bailey et al, 2007). The Communities that Care (CTC) programme also undertakes a detailed risk assessment. It is focused on risk at the community level with the objective of identifying those risks that preventative services should focus on within local areas. What we have been seeing, over the previous ten years, is RFA, at both the individual and community level, becoming embedded in the everyday practice of social care professionals.

\section{Challenges for risk factor analysis}


RFA has made a significant contribution to the prevention agenda, giving social science a voice in an important area of social policy. Until the mid-1990s social prevention remained marginalised in the work of Children's Services, being seen as making little contribution to the challenges that social workers and others faced (Parton, 2008). With the emergence of RFA came debate, dialogue and legislation, at both national and local level, which has given social prevention a central role in social work policy and practice frameworks (France and Utting, 2005). Its influence in areas such as Crime Prevention, Health Prevention Services and Children's Services in the UK should not be underestimated. Positive aspects of this influence have been a renewed commitment to social prevention and a rediscovery of the importance of 'social context' in how we understand the lives of vulnerable children and young people. Before New Labour social context and more sophisticated psychological perspectives were acknowledged only in a limited way. RFA has provided a new framework that has a place for social context and biography, and offers an alternative to the punitive measures that were the hallmark of prevention in the 1980s and 90s..

However, these positive aspects should not distract us from the problems with the RFA approach. Although RFA does have strong claims to be scientific, its evidence has to be approached with caution. While it does not usually claim to 'predict' which individuals will become a future social problem, RFA does suggest a causal relationship at an aggregate level. These research findings can be interpreted in unfortunate ways. For example, Stephen Scott, of the Institute of Psychiatry in the UK, reproduced in the British Government’s 2003 consultation paper Every Child Matters (DfES, 2003) a graph showing how half the children in his study who were viewed as anti-social at the age of eight could still be diagnosed as anti-social at the 
age of seventeen. This was then used as evidence for a causal relationship between early anti-social behaviour and future social problems. However. the same data can also show that a large number of false positives exist, in that over fifty percent of children did not go on to have any future social problems.

There are also problems concerning RFA's theoretical underpinnings and understandings of childhood and the life course. RFA starts from a set of assumptions about the notion of childhood as a developmental stage that leads to later outcomes through the unfolding of a predetermined programme (Sampson \& Laub, 2005). This perspective is dominated by what Taylor-Gooby and Zinn (2005) call the 'empiricist psychometric' approach. In this, childhood is seen almost as context-free and development is understood as linear and standardised (Hogan, 2005). While RFA has avoided the most reductionist elements of this approach through a limited recognition of context, the complexities of the life course that have been explicit in ecological perspectives on human development since the late 1970s (Bronfenbrenner, 1979) have tended to exert a minor influence. Paralleling these developments in psychology, in social theory and sociology approaches to understanding childhood have emerged that suggest that childhood cannot be separated from its social context (Prout, 2000) and that the life course is complex and varied dependent on a range of cultural, economic and political as well as psychological factors (France and Homel, 2006). For example, RFA has little to say about the wider structuring of life course opportunities, such as those created by the global impact on local labour markets and local employment opportunities (MacDonald, 2006). 
In the light of these criticisms of RFA, it is not surprising that we also argue that it fails to come to terms with the theoretical perspectives that drive social work practice. It assumes not only that a consensus exists over what the life course and childhood ‘is’ or should be, but also what the purpose of intervention should be. For example, Catalano and Hawkins (2000), in their discussion on theorising RFA suggest that there is a consensus in society about social norms and values and that we all know what is right and wrong or good and bad and therefore we "know the rules of the game” (p. 156). Most of our social problems amongst children emerge, they suggest, because they have failed to learn these norms or because adults do not give clear messages about what are acceptable or unacceptable forms of behaviour (Catalano \& Hawkins, 2000). Such a view fails to take into account the widespread ambiguity over values and norms and the complexity of how social problems might emerge. It also fails to recognise that the state and its agencies may actually contribute to the construction of social problems (France, 2008).

We have a related concern that RFA is a political project that has emerged, not because of 'new' evidence but because it helps the state manage 'risky individuals' or populations (Homel, 2005a). Risk assessment can be more concerned with governing risky populations from a distance (Webb, 2006) and with shifting the focus from need (Kemshall, 2006) than with ensuring that appropriate resources are made available to the most vulnerable. Not only does RFA create 'others' or 'outsiders' (Knepper, 2007) it also acts to screen out other possible explanations or causes of future social problems (Bessant, 2003). Risk, in this context is not some form of external reality but is a "calculative rationality" of governance where certain groups or individuals are identified as 'at risk' or 'high risk' (p. 255) and become monitored, observed, and 
managed by the state (Sharland, 2006). This is reinforced by the ways in which RFA plays into the popular discourse of 'sound bite’ politics. For example Pitts shows how, in political discussions, the focus has shifted from recognising a wide range of risk factors as key, to a view that sees a single risk factor linked to 'inappropriate parenting' as the focus for family policy. As a result parenting is prioritised and targeted not because it is the major risk factor but because it fits with government policy and objectives (Pitts, 2000).

Webb suggests this is especially relevant for social work practice in that risk assessment is presented as a value neutral process that provides technical solutions to a wide range of social problems. In social work there is what Webb calls a growth of the 'technologies of care'. These are concerned with the 'governance of uncertainty' (p. 142) or the management of risk whereby social work practice is being reshaped in late modernity:

Technologies of care are part of an assemblage of methodologies configuring social work within defined remits. They involve a certain unity of purpose with the field of possible objects; patterns of procedure and articulation; and regular rules for their operation.

(Webb, 2006 p. 142)

Risk assessment, in this context, is concerned with the routinisation of social work around performance management targets, focusing on 'tick box schedules' (p. 153). In this context risk factors are normalised and structured in such a way that alternative evidence is marginalised and the perspectives of children or their families remain 
unheard (Webb, 2006). Yet measuring risk factors, as a part of everyday practice, entails considerable difficulties (Crow et al, 2004;). Risk assessment is not a neutral process (Webb, 2006) and even when processes and forms such as ASSET are used, the personal judgements of probation and social workers remain hugely influential in shaping the assessment process (Baker, 2007).

\section{Recent developments in prevention science: relational developmental systems theories}

It is disturbing that RFA in all its forms is continuing to have such an impact, especially in the UK, given that internationally this way of thinking is by no means at the forefront of research and practice. As the American developmental scientist Richard Lerner put it recently,

Today, the cutting edge of the study of the human life span is framed by a developmental systems theoretical model, one that is informed by a postpositivist, relational metatheory that moves beyond classical Cartesian dichotomies ... and transforms fundamental antimonies into co-equal and indissociable complementarities.

Lerner \& Overton, 2008, p. 245

Amongst the antimonies that are now regarded as passé are the nature-nurture split, individual versus context, and the distinction between qualitative and quantitative change. A consequence of this postpositivist emphasis on contexts, relations and 
systems is a rejection of all forms of reductionism, including a focus on single factor 'causes' and the reduction of complex human change processes to a series of statistically derived risk factor scores. Certainly risk factors within this framework are understood as useful, since often simplification is necessary to grasp some important aspects of complex phenomena. However, RFA is regarded as one tool amongst many, and by no means the most important, especially when planning and implementing preventive interventions.

Understanding how intervention programs achieve (or not) their effects, particularly as they become larger and more complex, requires a theoretical frame that facilitates the analysis of changing individuals within changing contexts and societal institutions. Relational developmental systems models provide such a frame, viewing development as systematic and successive change in individuals or in other units of analysis that is associated with the dynamic relations over time among structures from multiple levels of organization (Lerner \& Castellino, 2002). These levels of organization range from the inner-psychological through the proximal social relational - especially within the context of the family - through local community levels to the sociocultural and social structural. Within this interdisciplinary perspective human agency and relative plasticity across the life course are central concepts, and family processes, social institutions and societal access routes that open up opportunities to take new directions are fundamental to the preventive enterprise (France \& Homel, 2006).

Perhaps most important for our present discussion, the basic unit of analysis in developmental systems models is relations, connections or transactions between 
individuals and contexts and between levels of organization (Homel, 2005b). The relation as the basic building block of a developmental system is fundamental not only to theoretical analysis and to measurement but also to preventive practice. Putting the proposition most simply, the effectiveness of preventive interventions designed to promote positive human development depends not only on the quality of specific contexts (such as home or school) or even the strength of the connections between such settings, but also on the extent to which activities in one setting reinforce, support or amplify the benefits of activities in other settings.

To illustrate what these abstract concepts might mean in real world settings, we draw in the remainder of this paper on the Pathways to Prevention Project, a long-term prevention initiative in a highly disadvantaged area of Brisbane, Australia. This project is important partly because it has been able to demonstrate both effectiveness and cost-effectiveness (Freiberg et al., 2005; Manning et al., 2006), but mostly because it is attempting to put into practice the principles of relational developmental systems theories.

\section{The Pathways to Prevention model: beyond risk factors}

Beginning with the Australian Government report by Homel and colleagues (1999), Pathways has evolved since 2001 as a comprehensive service offered through a partnership between national community service agency Mission Australia, local schools and Griffith University, in several ethnically diverse and socially disadvantaged Brisbane suburbs. In 1998-99 the rate of juvenile court appearances of adolescents resident in the area per 100010 -16 year olds was 158, nearly 8 times the 
Brisbane metropolitan area rate of 20. This was one reason why this area was selected for this experimental research-practice partnership, but other statistics such as income and unemployment levels that identified the area as socially vulnerable were also influential. Indeed, the process of area selection was probably the point at which traditional RFA was most influential in the development of Pathways, since as explained below risk factors or risk assessments are not used to identify or target children or families at risk. Although Pathways could be viewed as a targeted intervention because it is located in a disadvantaged area, within that area it has operated within a universal prevention framework through its presence in the community and in the seven state primary schools in the area.

In early 2009 there were 3757 children on the Pathways database, 2072 of whom were enrolled in one of the seven participating schools in 2008. A total of 441 children had been involved directly or indirectly through their families in the family support program (21.3\% of enrolled children), and 599 families had been entered on the Pathways database of participants by late 2008. Participation in Pathways is associated with a range of positive outcomes, including: reduced levels of difficult child behaviour; increased preschool language skills; improved Grade 1 school performance; and higher ratings of school readiness. Importantly, evaluation using a matched pairs quasi-experimental design has shown that the combination of enriched preschool programmes in concert with family support produced better outcomes than either on its own (Freiberg et al., 2005; Homel et al., 2006).

Within its universal focus, the Pathways model emphasises comprehensive and integrated practice that supports development in a holistic way. Its overriding goal is 
to create a pathway to wellbeing for all local children as they transit through successive life phases, from conception to youth. This approach stands in sharp contrast to single-focus programs that address specific risk factors by delivering defined content within a defined timetable (e.g., parenting courses for managing children’s behaviour). However, Pathways does incorporate many such programs within its wider mosaic of resources, while adapting them where necessary to local circumstances. These focused programs constitute some of the resources offered within a comprehensive range of support for children and their families. These support efforts are coordinated as far as possible to form cohesive networks that promote young people’s wellbeing in all areas of their development (social, emotional, cognitive, physical, spiritual). Development is understood as a complex and multi-faceted process that is influenced by a range of contexts and systems (e.g., families, schools, neighbourhoods, ethnic and spiritual communities), and by the relations between them.

As suggested by its name, the Pathways model for promoting children's wellbeing is organised around the concept of a developmental pathway, which refers to the way sequences of events, experiences and opportunities over time contribute to changes both within and around the child. This means that the framework for providing services must not only enhance the processes that bring about change within individuals, but also understand and enhance the changes taking place in their environments. Program activities are carefully constructed to enhance the environments of individuals in ways that create the possibility of better developmental outcomes. Within the Pathways model: 
1. The central goal of interventions is better outcomes for children and their families, now and across the life course.

2. Interventions in one context (e.g., the home) interact with, complement, and support interventions in other contexts (e.g., school).

3. Relationships, trust and cooperation between staff and clients are valued equally with evidence on what works.

4. Better individual outcomes are achieved by enriching all relevant developmental settings. Child-oriented programs are integrated with family support initiatives and programs introduced through appropriate systems such as schools, childcare and family health centres, or community groups.

5. Intervention effects are enhanced by focusing on life transitions (such as birth and starting school or high school) when people are both vulnerable and receptive to help.

6. A continuum of age-appropriate programs and resources is used to enhance developmental pathways over time.

7. Integrated practice is achieved through concerted efforts to build collaborative working partnerships between organisations, institutions and systems relevant to child and family wellbeing.

In the remainder of this section we amplify some of the above principles and provide three illustrations of how risk factors are identified, interpreted and transformed in the Pathways model. The third illustration is particularly pertinent to the second principle above, which is italicised because it is, as we argued earlier, one of the most critical consequences for practice of a relational developmental systems perspective.

\section{Risk factors as a lack of fit between elements of the developmental system}


Within the Pathways to Prevention model, risk factors are regarded as indicators of obstacles to the achievement of goals. For example, if a child lacks parental supervision, a common risk factor for engagement in youth crime, this is taken not as a sign of parental delinquency but as an indicator of parents or carers who need support of some kind to succeed in their parenting goals. It is also taken as a sign of systems failure, in the sense that schools and other caring agencies have failed in the past to respond adequately to the needs of this family (Homel, 2005b). Invariably the problems that are overwhelming the carers require resources that are currently beyond their means, but often through involvement in Pathways or referral to another service the family can work their way back to independence and to effective functioning. Thus information about 'risk' forms part of a broader analysis of the lack of fit between the resources required to meet needs within families and the wider community, and the resources actually available. This analysis is used to highlight the way various mismatches between strengths and needs limit access to the kinds of opportunities, privileges and resources that help guide individual pathways in positive directions.

Viewed from this perspective, risk is a form of inequality. It serves as evidence of a contextual or system-level failure to support development. It follows then that the intent of the intervention activities undertaken within the project is to:

(i) enhance the capacity of individuals, families and communities to gain access to resources and opportunities (that is to empower and promote efficacy)

(ii) contribute to reform of wider systems and social structures that limit options for certain members of society (that is, to establish processes for 
working within a developmental systems framework and to open up societal access routes).

\section{Risk, prevention science, and trusting relationships}

The concept of prevention amongst criminologists who work broadly within the prevention science paradigm is simple: identify key risk factors from longitudinal studies and select for implementation the most suitable program(s) from a menu of interventions tested in randomised controlled trials (Farrington, 2002). A major problem with this 'one size fits all' approach is that evidence comes in the form of 'program packages’ rather than models of practice that are flexible enough to comprehend local contexts and the challenges involved in achieving effective and sustainable engagement with local people and institutions. Successful practitioners, such as Hilton Davis (Braun, Davis \& Mansfield, 2006), have long struggled with how to conceptualise and properly value not just the scientific evidence on effective programs and the technical expertise of helpers, but also the qualities that make their work effective: respect, empathy, genuineness, humility, quiet enthusiasm, and personal integrity. The need for such qualities is inherent in the relational systems model and they are fundamental to effective prevention practice, but such interpersonal dynamics are presently largely ignored in the prevention science literature.

Consistent with the developmental systems emphasis on mutually influential relations, Pathways builds programs on the foundation of relationships with participants characterised by trust, cooperation, mutual caring and shared responsibility. 
Everyone, including the family being supported, participates on an equal footing to set goals, plan a way forward and then put those plans into action. Participation under these conditions, therefore, represents a form of empowerment in which staff and participants jointly recognise 'risks' and decide together how to deal with them. These qualities make the service accessible by the community it seeks to support. The service is also provided by people who see their role as agents of positive change in the lives of families and within the community, to which they maintain a long-term commitment. That is, the service is embedded as part of the community.

\section{Fragmentation of services as a risk: building mutually beneficial relations in the} developmental system

A major risk factor in disadvantaged communities is the way the experience of longterm adversity can contribute to the creation of a service delivery industry and a community that are mutually dependent (e.g., Kretzmann \& McKnight, 1993). In particular, there is a risk that separate agencies, each with their own eligibility criteria, are set up to address different issues so that families with complex needs are left to negotiate a maze of service options. When this occurs, families experience services in a piecemeal and fragmented way that reinforces their powerlessness and perpetuates dependence. To address this challenge Pathways strives to create an integrated system of care that not only involves families as active participants, but is able to respond in a holistic way to participants' complex needs. The aim is for professionals from different disciplines to extend their view of development and see their role in a wider sense that is not restricted to taking responsibility for one piece of the child's development (e.g., academic achievement, emotional health, positive parenting). 
Pathways family support staff forge partnerships with other service providers who have complementary expertise. So, for example, a teacher who recognises that a child's health may be affecting his/her capacity to participate as an active learner at school may work with a Pathways staff member to help the child's family access appropriate health services. Subsequent feedback about the child's health status enables the teacher to respond by accommodating the child's needs in her instructional practice.

The Circles of Care programme in Pathways is designed specifically to strengthen these kinds of working partnerships between children, parents, schools and community agencies. Circles of Care takes two forms: targeted and universal. In the targeted form, the key step is to set up a small Circle for each participating child. A Circle usually consists of a child identified as needing extra support, the teacher, family support staff, parents or carers, and community members who commit to work together over time in support of the child. The idea is to create supportive environments by focusing on the task of building relationships and connections across the systems and contexts that are critical to children: most notably their families, schools and cultural communities.

The universal version of Circles aims to create a circle of care around an entire class to facilitate the transition to school. This time the Circle consists of the teacher and all the parents, supported by a Pathways worker and other personnel as required. Work begins prior to school through such methods as playgroups, and continues through the first year of enrolment by providing direct access to family support and creating 
opportunities for families to become involved in their children's learning. The goal is to link families, schools, and community agencies and ensure that each child's experiences at home and school reinforce each other to promote positive development.

\section{Conclusion}

Over the past ten years, risk factor analysis has had a significant role in shaping prevention practice around the world. It has infiltrated not only the policy nexus of social work but also social work training (Crisp et al, 2005) and the everyday practice of those working with vulnerable and challenging children and families. RFA has brought new evidence and thinking to the debates about social prevention and has given politicians a framework for implementing intervention programmes with children and young people most 'at risk'. Yet as we have shown RFA has its limitations and is open to political (and practice) abuse that can increase risk for some of the most vulnerable children and young people.

A critical gap in RFA is its lack of a sophisticated theoretical foundation that offers an adequate account of developmental processes. Not only does it fail largely to incorporate basic features of social ecological analyses (Brofenbrenner, 1979) it is unable to accommodate the socio-cultural features of childhood and youth and the broader social processes, identified by disciplines such as sociology and cultural theory, that shape the life course. By drawing upon a developmental systems model we can show how changing behaviour can be understood through a holistic theory of social life that adequately contextualises individual and social change. What then 
becomes central to prevention policy and practice is the focus on changing institutional systems, opening up societal access routes and prioritising relationships, connections and transactions.

In our discussion of the Australian Pathways to Prevention programme, while not rejecting RFA, we have shown that we need an approach that goes beyond the individual focus that RFA tends to encourage, offering a framework that allows the whole child in their whole environment over the whole of their childhood to become the focus of preventive action. The purpose of intervention is not only to modify proximal developmental settings such as the family or the classroom in ways that create the possibility of individual change, but to build the capacity of the whole developmental system. This is achieved by strengthening connections and enhancing the relational context of intervention to ensure that activities and resources in one context complement and reinforce activities in other contexts. Better integrated community services are important in this process, but more fundamental is the need for structural and cultural changes within key developmental institutions such as education or childcare that reduce sectoral silos and enable the developmental system to work more effectively on behalf of vulnerable children and young people.

\section{References}

Bailey, S., Vermeiren, R., and Mitchell, P. (2007) Mental health, risk and antisocial behaviour in young offenders. In Blyth, M., Solomon, E., and Baker, K. Young People and 'risk' Bristol, Policy Press 
Baker, K. (2007) 'Risk in practice: systems and practitioner judgement' in Blyth, M., Solomon, E., and Baker, K. Young People and 'risk' Bristol Centre for Crime and Justice Studies, Policy Press

Bessant, J., Hil, R., Watts, R. (2003) ‘Discovering’ Risk, Oxford, Peter Lang Berry, M. (2007) Effective Approaches to Risk Assessment in Social Work: An International Literature Review, Edinburgh, Scottish Executive.

Beinart, S., Anderson, B., Lee, S. and Utting, D. (2002) Youth At Risk? A National Survey of Risk Factors, Protective Factors and Problem Behaviour Among Young People in England, Scotland and Wales. London: Communities That Care

Braun, D., Davis, H. \& Mansfield, P. (2006). How helping works: towards a shared model of process. London, UK: Parentline Plus

Bronfenbrenner, U. (1979). The ecology of human development: experiments by nature and design. Cambridge, Mass.: Harvard University Press

Catalano, R. and Hawkins, J.D. (2000) 'The Social Development Model: A Theory of Antisocial Behaviour’ in Hawkins, J.D. Delinquency and Crime, Cambridge, Cambridge University Press. 
Crisp, B., Anderson, M., Orme, J., and Lister, P. (2005) Learning and Teaching in Social Work Education: Text Books and Frameworks for Assessment, Bristol, Policy press

Crow, I., France, A., Hacking, S., and Hart, M. (2004) Does CTC Work? The Evaluation of Communities that Care Demonstration Projects. York, Joseph Rowntree Foundation.

Department for Education and Skills (2003) Every Child Matters, London, HMSO

Department for Children, School and Families (2008) Ten Year Children's Plan, London, DSCF.

Elder, G.H. Jr., Kirkpatrick Johnson, M. \& Crosnoe, R. (2004). The emergence and development of life course theory. In Jeylan T. Mortimer \& Michael J. Shanahan (Eds.), Handbook of the life course (pp. 3-22). New York: Springer.

Farrington, D.P. (2002). Developmental criminology and risk-focused prevention. In M. Maguire, R. Morgan \& R. Reiner (Eds.), The Oxford handbook of criminology (3rd edn., pp. 657-701). Oxford: Oxford University Press.

Fergusson DM \& Horwood LJ. (2001). The Christchurch Health and Development Study: Review of findings on child and adolescent mental health. Australian and New Zealand Journal of Psychiatry, 35: 287-296. 
Fergusson DM, Grant H, Horwood L J \& Ridder E. (2005). Randomized trial of the Early Start Program of home visitation. Pediatrics 116(6): e803-e809.

France, A. (2008). Risk Factor Analysis and the Youth Question. Journal of Youth Studies, 11(1), pp. 1-15.

France, A. and Homel, R. (2006) Societal access routes and developmental pathways: Putting social structure and young people's voice into the analysis pathways into and out of crime in Australian and New Zealand of Criminology, Vol. 39.3 pp287 -294

France, A. and Utting, D. (2005) 'The paradigm of 'risk and protection-focused prevention' and its impact on services for children and families.' Children and Society, 19. No.2 pp $77-90$

Freiberg, K., Homel, R., Batchelor, S., Carr, A., Lamb, C., Hay, I., Elias, G. \& Teague, R. (2005). Pathways to participation: A community-based developmental prevention project in Australia. Children and Society, 19: 144-157.

HM Treasury (2002) Spending Review, London, HMSO 
Hawkins, J. D., Catalano, R. F., \& Arthur, M. W. (2002). Promoting science-based prevention in communities. Addictive Behaviors, 27, 951-976.

Hogan, D. (2005) 'Researching 'the child’ in developmental psychology. In Greene, S. and Hogan, D. (2005) Researching Children’s Experience, London, Sage.

Homel, R. with Interdisciplinary Research Team (1999). Pathways to prevention:

Developmental and early intervention approaches to crime in Australia (Full Report, Summary and Appendices) (400 pages). Canberra: Australian Government Publishing Service. (Available via www.griffith.edu.au/professional-page/professor-rosshomel/publications/children-and-communities)

Homel, R. (2005a). The puzzles and paradoxes of youth crime prevention. Safer Society, 27 Winter: 2-4. London: NACRO

Homel, R. (2005b). Developmental crime prevention. In Nick Tilley (Ed.), Handbook of crime prevention and community safety (pp. 71-106). Cullumpton, Devon, UK: Willan Publishing

Homel, R., Freiberg, K., Lamb, C., Leech, M., Hampshire, A., Hay, I., Elias, G., Carr, A., Manning, M., Teague, R. \& Batchelor, S. (2006). The Pathways to Prevention Project: The First Five Years, 1999-2004. Sydney: Griffith University \& Mission Australia. http://www.griffith.edu.au/centre/kceljag/ (via Pathways link) 
Jonkman, H., Junger-Tas, J., and Van Dijk, B. (2005) 'From behind Dikes and Dunes: Communities that Care in the Netherlands' Children and Society,19 No. 2 pp 105 116

Kemshall, H. (2006) Risk assessment and risk management: the right approach?

Blyth, M., Solomon, E., and Baker, K. Young People and 'risk’ Bristol, Policy Press

Knepper, P. (2007) Criminology and Social Policy, London, Sage.

Kretzmann, J., \& McKnight, J. (Eds). (1993). Building communities from the inside out: a path toward finding and mobilising a community's assets. Evaston, Ill: Institute for Policy Research.

Lerner, R. \& Castellino, D. (2002). Contemporary developmental theory and adolescence: developmental systems and applied developmental science. Journal of Adolescent Health 31, 122-135.

Lerner, R. \& Overton, W. (2008). Exemplifying the integrations of the relational developmental system: Synthesizing theory, research, and application to promote positive development and social justice. Journal of Adolescent Research. 23: 245-255

MacDonald, R. (2006) Social exclusion, youth transition and criminal careers: five critical reflections on 'risk'. Australian and New Zealand Journal of Criminology Vol. 39 Issue 3 pp371-383 
Manning, M., Homel, R., \& Smith, C. (2006). Economic evaluation of a communitybased early intervention program implemented in a disadvantaged urban area of Queensland. Economic Analysis and Policy, 36(1 \& 2), 99-120.

Moffitt, T. E. (1993). Adolescence-limited and life-course-persistent antisocial behavior: A developmental taxonomy. Psychological Review, 100(4), 674-701.

Muncie, J. (2005). The Globalization of crime control - the case of youth and juvenile justice. Theoretical Criminology 9 (1): 35-64.

Parton, N. (2008) 'The ‘Change for Children’ Programme in England: Towards the 'Prevention- Surveillance State’ Journal of Law and Society, Vol. 35 Number 1 pp $166-$

Pitts, J. (2000) ' The New Youth Justice and the Politics of Electoral Anxiety' in Goldson, B. (2000) The New Youth Justice, Lyme Regis, Russell House Publishing.

Prior, M., Sanson,A., Smart, D. \& Oberklaid, F. (2001). Pathways from infancy to adolescence: Australian Temperament Project 1983-2000. Melbourne; Australian Institute of Family Studies

Prout, A. (2000) The Body, Childhood and Society, London, Palgrave. 
Sampson, R. J., \& Laub, J. H. (2005). A general age-graded theory of crime: Lessons learned and the future of life-course criminology. In D. P. Farrington (Ed.), Advances in criminological theory, Volume 13: Testing integrated developmental/life course theories of offending (pp. 165-181). New Brunswick, NJ: Transaction Publishers.

Sharland, E, (2006) Young People, Risk Taking and Risk Making- Some thoughts for Social Work, British Journal of Social Work, 36 pp247 - 265

Taylor-Gooby and Zinn (2005) Risk in Social Science, London, Oxford University Press

Webb, S. (2006) Social Work in a Risk Society, Basingstoke, Palgrave

West, D.J. and Farrington, D. (1977) The Delinquent Way of Life. London, Heinemann. 